\title{
Local air quality management as a policy cycle in the cities of Newcastle and Lake Macquarie, Australia
}

\author{
L. Graham \& H. Bridgman \\ School of Environment and Life Sciences, University of Newcastle, \\ Australia
}

\begin{abstract}
In the air policy frameworks of the Australian Commonwealth and New South Wales (NSW) Governments, responsibility for the major air pollution sources and assessment of regional air quality lies beyond the direct mandate for local government. However, local government is responsible for a wide range of smaller sources. By contrasting the responses to air pollution by the local councils in the cities of Newcastle and Lake Macquarie, this paper contributes to the understanding of local air quality management in NSW. The paper builds on the concept that air quality management requires a basic scientific and decision-making framework. First, we discuss air quality management as a policy cycle and introduce the concept of policy networks to illustrate their role in formulating local environmental policy. Second, we compare and contrast the aspirations, capacities and achievements of the two local councils in relation to air quality management from 1995 to 2005 . Third, we examine the contribution to the policy cycle of new tools that use computer-based geographic information systems (GIS), namely, the air emissions inventory and air quality modelling (using The Air Pollution Model (TAPM)). Together, these tools offer advances in the knowledge of local air pollution science and a technological capacity to predict the impact of management options, heralding a paradigmatic change in local air policy making in NSW.

Keywords: local air quality management, scientific decision making, policy cycle, policy network, GIS, emissions inventory, air pollution modelling, TAPM.
\end{abstract}

\section{Introduction}

Air quality management requires a basic scientific and decision making framework, consisting of tested tools and procedures that support a process of 
mediation between political, social, economic and technological influences that propose and oppose air pollution control (Elsom and Longhurst [1]). The framework for air quality management recommended by Elsom and Longhurst [1] implied a link with the scientific method of problem solving. Bridgman [2] conceptualised air quality management as a process and prescribed a framework of operations leading to active strategies and a scientific approach to reducing air pollution. Successful completion of the sequence of procedures implied the integration of air science, policy and management. These ideas comprise the main themes underlying this paper.

This discussion builds on the frameworks recommended by Elsom and Longhurst [1] and Bridgman [2] by further interpreting air quality management as a policy cycle. The paper begins with a background that briefly outlines the development of a scientific approach to air quality management in Australia. In the main sections of the paper we focus on local air quality management as a policy cycle within local government. In conclusion, we recommend a framework to assist local councils to effectively integrate science, policy and air quality management within current legislation.

\section{Background}

During 1994-1998, the Australian Commonwealth Government negotiated roles and responsibilities for national, state and territory and local governments to develop a consistent approach to air quality management. An independent inquiry into urban air pollution assessed scientific knowledge of air pollutants and impacts, and reviewed the emission standards and ambient monitoring goals of states and territories [3]. The National Environment Protection Council (NEPC), set broad statutory frameworks of agreed national objectives for environmental protection from air pollution. The National Environment Protection Measure (Ambient Air Quality) [4] specified goals and protocols for monitoring and reporting and allocated state and territory governments the responsibilities: first, to establish nationally accredited air quality monitoring networks for major urban air pollutants; second, to report annually on compliance with national air quality standards; and third, to report on actions taken to mitigate air pollution. The individual state and territory governments determined the details of their air policy frameworks (Graham and Bridgman [5]).

The air quality management plans developed for the metropolitan centres evolved via the policy making process identified by Elsom and Longhurst [1] and Bridgman [2]. The policy responses to air pollution for the major urban centres of Sydney, Brisbane, Melbourne and Perth addressed similar issues, targeting reduced emissions from transport, industrial and commercial premises and domestic activity. These developments established a scientific and consultative approach to air policy in Australia (Graham and Bridgman [5])

However, the Commonwealth and NSW Government air policy frameworks constrained the response of local governments within statutory and financial limits. For example, the NSW Government held the statutory power to regulate 
major industrial sources and the Commonwealth Government held power to regulate motor vehicle emissions and fuel quality standards While local governments reported annually on air quality, they were required neither to assess air quality by health-based national standards nor to develop action plans for areas experiencing poor air quality. Neither Commonwealth nor NSW Governments were required to provide guidance or financial resources to local governments for air quality management. Nevertheless, in the 1990s, innovative local councils such Newcastle City Council (NCC) and Lake Macquarie City Council (LMCC) (Figure1) initiated non-statutory policies to improve air quality, aspiring to transfer to the local level the tools and procedures applied to air quality management in the metropolitan centres $[2,6,7,8,9]$.

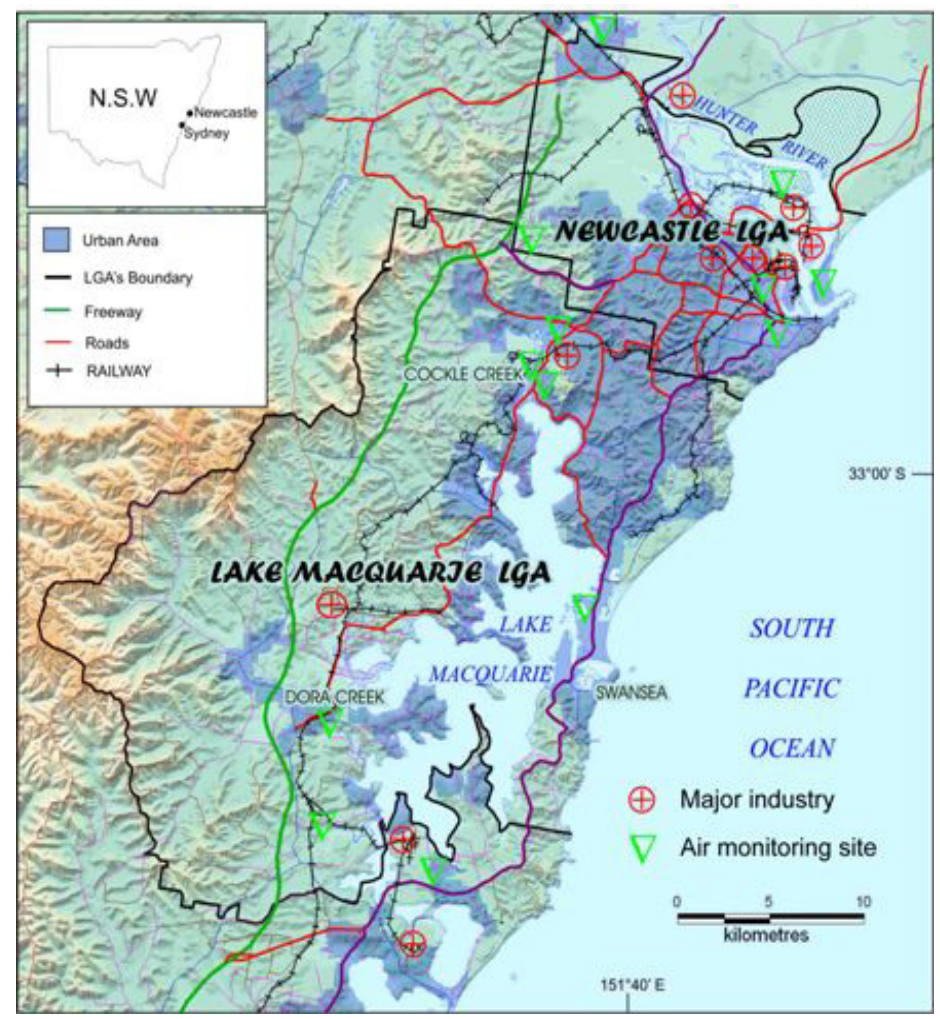

Figure 1: Location of the local government areas of Newcastle and Lake Macquarie on the central coast of New South Wales, eastern Australia.

\section{Air quality management as a policy cycle}

Considering air quality management as a policy cycle identifies the factors that influenced the integration of air science, policy and management at NCC and 
LMCC. Like the models of public policy making, Bridgman's [2] framework allowed investigation of stages in the policy-making process and consideration of the factors influencing progress from one stage to the next. The approach parallels the phases in the scientific method of applied problem solving and the stages in the public policy cycle (Table 1). For example, Bridgman's [2] Stages 1 to 4 correspond to Lasswell's [10] first stage in public policy-making, described as intelligence collecting and processing and dissemination to decision-makers. Similarly, Howlett and Ramesh [11] interpreted the first stage of the public policy cycle as agenda setting, the process by which problems came to the attention of governments. They also acknowledged the parallel between agenda setting and 'problem recognition', which defined the first stage of the scientific method of applied problem solving. Similarly, Bridgman's [2] subsequent Stages 5 to 9 correspond with the subsequent stages of public policy-making and applied problem solving (Table 1).

\subsection{Committees as policy networks for steering the policy cycle}

Critics of public policy science identified the limitations of the linear models of the policy cycle exemplified in Table 1. First, the implication of a rational, systematic and linear procedure misinterpreted the significance of the non-linear process in practice (Sabatier and Jenkins-Smith [12]). Second, the models offered no pointers as to what or who drives a policy from one stage to the next. Third, the linear models provided no account of the infrequent but paradigmatic changes in policymaking produced by advances in science or technology. Howlett and Ramesh [11] identified the need for more accurate descriptions that acknowledged the roles of actors within the policy cycle and that explained why policies tend to develop and change through a process of paradigm shifts.

The concept of policy networks emerged in public policy research to describe the dynamic networked interactions between stakeholders who negotiated, formulated and developed public policy $[11,12,13] . \mathrm{M}^{\mathrm{c}}$ Guirk [14] interpreted policy networks as the powered-up sites in which policy options are generated. This discussion applies the term broadly to describe the interactions of decision makers who meet regularly in formalised committee structures to drive the environmental policy cycle. For example, the Local Agenda 21 Program [15] and the Cities for Climate Protection Australia Program [16] acknowledge the essential role of a cross-sectoral multi-disciplinary committee or network to drive policy making processes that parallel the stages of applied problem solving and the public policy cycle (Table 1).

\subsection{Contrasting air policy at Newcastle and Lake Macquarie}

NCC and LMCC set common goals in 1995-1996, aspiring to achieve leadership in local government action to reduce air pollution and to maintain partnerships with stakeholders $[6,9]$. NCC established a scientifically informed decisionmaking framework, coordinated by a committee of decision-makers who represented cross-sectoral interests and the community. NCC collated ambient air monitoring data and reported to the community. 
Air Pollution XIV 199

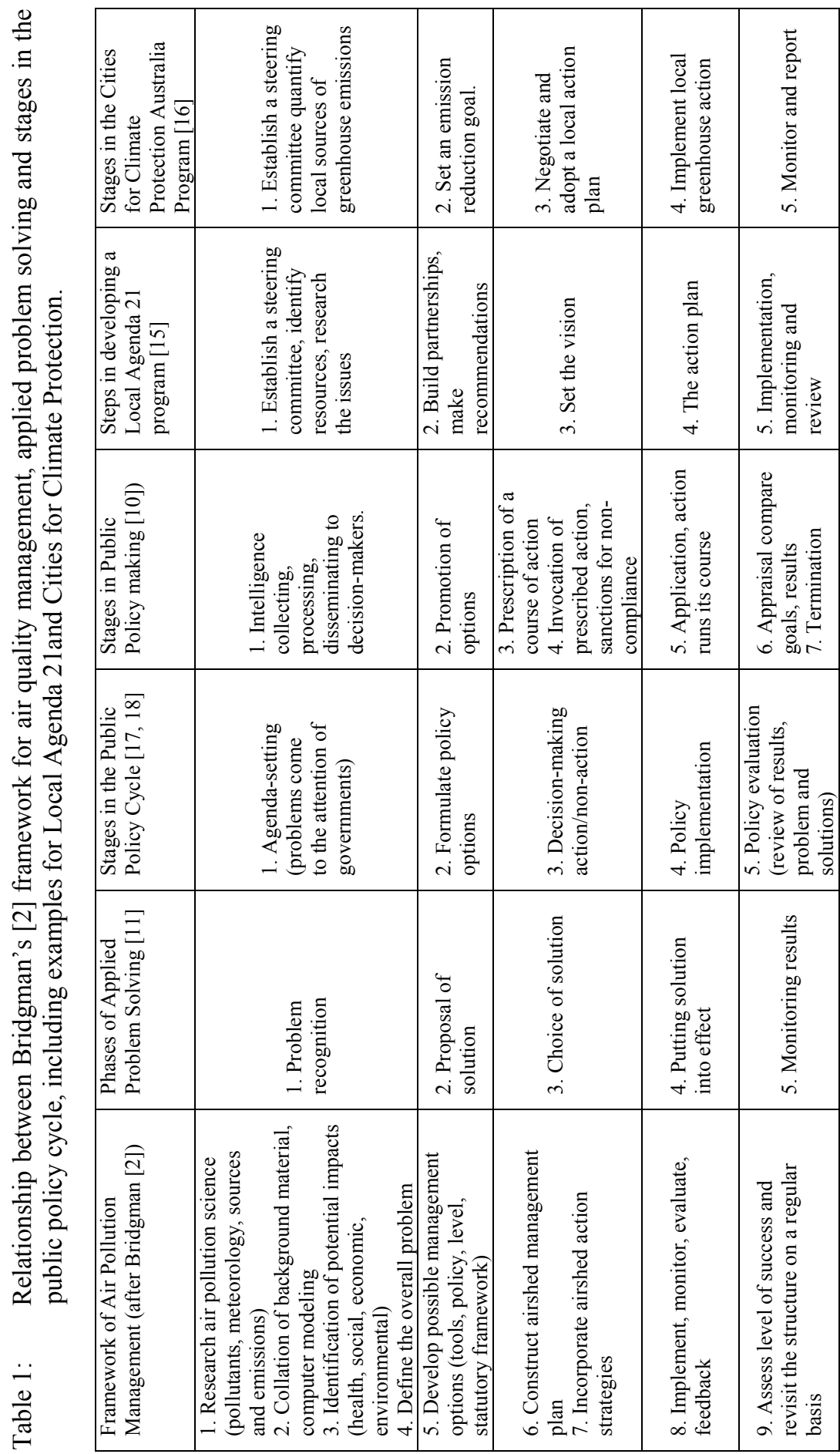

WIT Transactions on Ecology and the Environment, Vol 86, (C) 2006 WIT Press www.witpress.com, ISSN 1743-3541 (on-line) 
Research assessed the contribution to decision-making of new tools to assist air quality management, that is, the air emission inventory and air pollution modelling $[19,20]$. The research findings informed air policy and urban planning. During 1998-2005, NCC completed two phases of the policy cycle, demonstrating successful integration of air pollution science, policy and management $[7,8]$.

In contrast, $\mathrm{LMCC}$ failed to assemble the components recommended for a decision-making framework dedicated to air policy. LMCC lacked a system for community reporting of air quality data from industry-operated monitoring sites in the local government area. Although LMCC sponsored the compilation of an air emissions inventory and applications of air pollution modelling [21, 22], that is, tools to assist achievement of the goals set in 1996, LMCC failed to make a policy response to the research findings and failed to integrate the tools into a framework for future air quality management and urban planning [23].

Contrasting committee structures accompanied the contrasting capacities of NCC and LMCC to integrate air science and policy, steering the Councils' environmental agendas in different directions. NCC has a strong history of air pollution concern, and commenced collaborative action to improve air quality, in 1947, via the Smoke Abatement Advisory Panel which represented proponents and opponents of air pollution control [2]. Currently, the Newcastle Environment Protection and Air Pollution Advisory Committee (EPAPAC) facilitates and reviews air policy, maintains political commitment and attracts external expertise, guidance and financial support. Membership consists of community, industry, council, and scientific representatives.

In contrast, LMCC historically lacked a formalised air policy network to drive the policy cycle towards the air quality objectives set in 1996. LMCC policy documents provide no evidence for the air policy cycle progressing beyond the preliminary air quality study [21]. In 2004, an internal committee reviewed pre-existing policies, selecting strategies to be carried forward into the Lake Macquarie Environmental Action Plan (LMEAP, [23]). The interests of industry and coastal management rather than air pollution reduction dominated the environmental policy cycle. The LMEAP [23] addressed water pollution and greenhouse gases, and excluded actions to target sources of industrial and urban air pollution, for which local councils hold responsibility. These examples suggest that the interests of the policy network that coordinates the decisionmaking framework dynamically influence the direction and progress of the environmental policy cycle.

\subsection{Catalysts for more scientifically and socially relevant air polices}

Based on comparisons of national ambient air monitoring data and health based air quality goals set in the 1990s, the traditional approach to air quality management provides limited biophysical descriptors of local air pollution science and outmoded indicators of the health risks of air pollution [24]. New air quality management tools that use computer-based geographic information systems (GIS), namely, the local air emissions inventory and outputs for air quality models, offer local government organisations a new technological 
capacity to support policy decision-making in air quality management and urban planning.

Table 2: The contribution of GIS-based air quality management tools to the local government air policy cycle [19, 22].

\section{Stage 1 Researching air pollution science}

The GIS-based air emission inventory graphically presents air pollution as spatially disaggregated, quantified estimates of various pollutants from industrial, mobile, commercial and domestic sources in the local government area. It provides a technical basis for comparing changes in emissions, resulting from air impacts of urban planning.

\section{Stage 2 Collating background material and computer modelling}

The inventory provides input data for the GIS-based air pollution model (TAPM) which in turn provides a tool to assist the policy network to conceptualise the dynamics of local air pollution science. TAPM presents graphic representations of the interplay of local meteorology, terrain, air emissions and air pollution dispersion. For example, in the Newcastle case study, TAPM predicted that the highest concentrations of $\mathrm{PM}_{10}$ most likely occurs in the industrial-residential suburbs during winter night times, under temperature inversions.

\section{Stage 3 Identifying the potential impacts of air pollution}

The inventory and TAPM contribute information in terms of spatial distribution across the local area which offers a more sophisticated and biophysically accurate representation that data from ambient air monitoring sites. The information offers potential for use in methodologies to estimate heath impacts and economic costs of specific air pollutants and sources,

\section{Stage 4 Defining the problem}

The air emission inventory and TAPM offer policy makers an improved biophysical explanation of the complexity of the atmosphere and air pollution, compared to the explanation derived from national air quality monitoring data. For example, the inventory describes local air science in terms of a geographical distribution of air emission sources and estimated quantities of the criteria pollutants. That is, it provides new knowledge on the 'what', 'where from' and 'how much' regarding local air pollutants. TAPM demonstrates graphically and statistically the spatial and temporal impacts of factors affecting local air pollution dispersion. That is, it provides new knowledge of the 'where does it go', 'how much' and 'when' regarding the dispersion of air pollution emissions. For example, analysis of TAPM outputs for Newcastle and Lake Macquarie identified localities remote from the monitoring network that were likely to experience elevated $\mathrm{PM}_{10}$ and $\mathrm{SO}_{2}$ concentrations, exceeding national air quality standards. TAPM predictions, displayed as a three-dimensional visualization, allow complex definitions of local air pollution as a source of broader environmental problems. For example, TAPM's capacity to estimate acid deposition offers technical information that opens debate to the role of air pollution in the degradation of land and water environments of Lake Macquarie.

\section{Stage 5 Developing possible management options}

$T A P M$ allows policy makers to explore the cumulative impacts of options to reduce air pollution and changes in land use. For example, the TAPM applications for NCC and LMCC demonstrated that motor vehicles and urban development threaten air quality less that a new low emission industrial point source.

\subsubsection{The contribution of GIS based emissions inventories and modelling}

In contrast to descriptions of local air quality based on ambient air monitoring data, the GIS based air emissions inventory provides new information (Table 2). For example, the NCC inventory identified motor vehicle emissions, rather than industry, as the city's major source of precursor pollutants for photochemical smog [20]. For NCC, a challenge within EPAPAC had been the resolution of scepticism towards technical expertise that suggested that increased mobile and area-based emissions presented a relatively much greater threat to current air quality than industrial development. Via illustration and discussion, the NCC 
applications of the air emissions inventory, and air quality modelling results [19] (using The Air Pollution Model, TAPM [25]), moved EPAPAC beyond conflict associated with out-dated concepts of local air pollution science and focused management towards reducing vehicle emissions and integrating air quality management with urban planning and transport policy at local and state levels. Compared with perceptions of local air quality based on comparison of the national ambient air monitoring data and national air quality goals, the GIS based tools offered descriptions of complexity of the atmosphere and air pollution that were more biophysically accurate, allowing policy formulations for air quality management and urban planning that were more socially relevant. The example of NCC represents a paradigm shift in local air policy making in NSW.

\subsubsection{Other components in the decision-making framework}

Access to other recommended components in a decision-making framework influences the air policy cycle within local councils, namely: public access to ambient air monitoring data (despite inherent limitations); the existence of an action plan for improving air quality; the influence of local geography, environmental priorities and financial resources of the local council; and the culture of innovation and technical training opportunities within the council. Detailed analysis and evaluation of the roles of such factors exceeded the scope of this paper.

\section{Conclusion}

This discussion has highlighted the interrelated roles of a range of factors influencing local government air policy. Most evident was the pivotal role of the local councils' committee structures in driving or not driving the air policy cycle. The example of LMCC demonstrated that, first, the setting of goals to achieve leadership and the proposing of actions to reduce air pollution, while documented in a policy, do not guarantee the implementation of the actions to achieve the goals. Second, while the GIS-based tools, the air emissions inventory and the air quality model, provide new information in the initial stages of defining the scope of local air quality issues, and offer the potential to act as catalysts in the policy cycle, their application alone is insufficient for guaranteeing the progress of the policy cycle. Third, the exclusion of decisionmakers who represent the interests of reducing urban air pollution potentially steers the environmental policy cycle away from urban air policy. In contrast, NCC demonstrated the success of a local air policy, within statutory limits.

To assist local councils to effectively integrate science, policy and air quality management within current NSW legislation, we recommend that a framework includes: a steering committee dedicated to air policy and representing crosssectoral interests and the community; a GIS-based air emissions inventory; application of an air pollution model, such as TAPM; an action plan to reduce urban air pollution emissions and community reporting of health based air quality information. For the future, potentially our examples support an opening of debate to consider a new and broader role for local government, extending the 
paradigm shift in air policy-making to the Commonwealth and State Governments in Australia.

\section{References}

[1] Elsom, D.M, and Longhurst, J.S.W., Local and regional aspects of air quality management: an overview (Chapter 1). Regional and Local Aspects of Air Quality Management, eds. D. Elsom and J Longhurst, WIT Press: Southampton, pp. insert pages, 2004.

[2] Bridgman, H.A., Air pollution management in Australia: The example of Newcastle, NSW (Chapter 6). Air Quality Management, ed J.S.W., Longhurst, D.M. Elsom and H. Power, WIT Press, Southampton UK, pp.159-198, 2000.

[3] AATSE, Urban Air Pollution in Australia, ed. Australian Academy of Technical Sciences and Engineering: Parkville, 1997.

[4] Commonwealth of Australia, National Environment Protection Measure for Ambient Air Quality, National Environment Protection Council, Environment Australia: Canberra, 1998.

[5] Graham, L. and Bridgman, H.A., Air quality management in Australia (Chapter 2). Regional and Local Aspects of Air Quality Management, ed. D. Elsom and J Longhurst, WIT Press: Southampton, pp.15-50, 2004.

[6] Newcastle City Council, Newcastle Environmental Management Plan, 1995.

[7] Newcastle City Council, Newcastle Airshed Management Action Plan, 1997.

[8] Newcastle City Council, Newcastle Airshed Management Action Plan, 2005.

[9] Lake Macquarie City Council, Lake Macquarie Environmental Management Plan, 1996.

[10] Lasswell, H.D., The Decision Process: Seven Categories of Functional Analysis, University of Maryland: Maryland 1956.

[11] Howlett, M.H. and Ramesh M., Studying Public Policy: Policy Cycles and Policy Subsystems, Oxford University Press: Oxford, 1995.

[12] Sabatier, P.A and Jenkins-Smith, H.C., The Advocacy Coalition Framework: Assessments, Revisions, and Implications for Scholars and Practitioners. Policy Change Learning: An Advocacy Coalition Approach, eds, P.A. Sabatier and H.C. Jenkins-Smith, Westview; Boulder, 1993.

[13] Rhodes, R.A.W, Understanding Governance: Policy Networks, Governance, Reflexivity and Accountability, Open University Press, Buckingham 1997

[14] McGuirk, P., Power and policy networks in urban governance: Local government and property-led regeneration in Dublin, Urban Studies, 37(4) pp. 651-672, 2000.

[15] Agenda 21:Programme of action for sustainable development, document adopted at the United Nations Conference on Environment and 
Development Rio de Janeiro, Brazil, 3 to 14 June 1992 http://www.sidsnet.org/docshare/other/Agenda21 UNCED.pdf.

[16] Cities for Climate Protection $^{\text {TM }}$ Australia Program, http://www.greenhouse.gov.au/local/ccp/index.html.

[17] Brewer, G.D., The Policy Sciences Emerge: To Nurture and Structure a Discipline, Policy Sciences, 5(3) pp. 239-44, 1974.

[18] Jones, C.O. An Introduction to the Study of Public Policy, Brooks/Cole: Monterey, 1984.

[19] Newcastle City Council, Newcastle Air Emissions Inventory, 2004.

[20] Graham, L., and Bridgman, H., Applying the CSIRO Air Pollution Model to the Newcastle Airshed, Report to the Newcastle City Council, The University of Newcastle, 2004.

[21] Hunstone, M., Lake Macquarie Preliminary Air Quality Study, Lifestyle 2020, Lake Macquarie Council1, 1998.

[22] Graham, L., and Bridgman, H., Applying the CSIRO Air Pollution Model to the Lake Macquarie Airshed, A Report to the Lake Macquarie Environmental Research Grants Council, The University of Newcastle, NSW, 2002.

[23] Lake Macquarie City Council, Lake Macquarie Environmental Action Plan, Lake Macquarie, 2004.

[24] WHO Europe, Health Aspects of Air Pollution - Results From The WHO Project Systematic Review Of Health Aspects Of Air Pollution In Europe, Regional Office for Europe of the World Health Organization, Copenhagen, Denmark 2004, http://www.euro.who.int/document/E83080.pdf.

[25] Hurley, P., The Air Pollution Model (TAPM) Version 1: Technical Description and Examples, CSIRO Atmospheric Research Technical Paper No. 43, Commonwealth Scientific and Industrial Research Organisation, Melbourne, 1999, http://www.dar.csiro.au/res/aq/TAPM. 